\begin{tabular}{l|l|l} 
Jurnal Eksplorasi Akuntansi & $\begin{array}{l}\text { ISSN : 2656-3649 (Online) } \\
\text { hol. 1, No 3, Seri A, Agustus 2019, Hal 906-921 }\end{array}$
\end{tabular}

\title{
PENGARUH SKEMA KOMPENSASI DAN SELF EFFICACY TERHADAP BUDGETARY SLACK: SEBUAH STUDI EKSPERIMEN
}

\author{
Mesrawati Candra1, Nayang Helmayunita ${ }^{2}$ \\ 1)Alumni Jurusan Akuntansi Fakultas Ekonomi Universitas Negeri Padang \\ 2)Jurusan Akuntansi Fakultas Ekonomi Universitas Negeri Padang \\ *Korespondensi: watimesra91@gmail.com
}

\begin{abstract}
This study aims to prove empirically about: 1) differences in the effect of truth inducing and slack inducing compensation schemes on budgetary slack, 2) differences in the effect of high and low self efficacy on budgetary slack, 3) the effect of interaction compensation schemes and self efficacy on budgetary slack. This study uses a quasi-experimental method with a group of research subjects who are students majoring in Accounting in the 2016 bachelor year of the Faculty of Economics, Padang State University. The sampling technique is total sampling. The population in this study amounted to 107 students. The source of research data is primary data using working paper in the form of coding or translating letters into numbers. Data analysis using two ways ANOVA test. The results of this study concluded that compensation schemes can affect lower-level managers in conducting budgetary slack, self-efficacy affects lower-level managers in conducting budgetary slack, and the influence of interaction compensation and selfefficacy schemes on budgetary slack.
\end{abstract}

Keywords: compensation scheme; self efficacy; budgetary slack

How to cite (APA $6^{\text {th }}$ style)

Candra, M., \& Helmayunita, N. (2019). Pengaruh Skema Kompensasi dan Self Efficacy Terhadap Budgetary Slack: Sebuah Studi Eksperimen. Jurnal Eksplorasi Akuntansi, 1(3), Seri A, 906-921.

\section{PENDAHULUAN}

Perusahaan ataupun organisasi memiliki tujuan yang akan dicapai di masa depan, salah satu cara untuk mencapai tujuan tersebut yaitu dengan menyusun perencanaan. Penganggaran merupakan salah satu bentuk perencanaan yang baik. Menurut Mardiasmo (2002:61), anggaran merupakan pernyataan mengenai estimasi kinerja yang hendak dicapai selama periode waktu tertentu yang dinyatakan dalam ukuran finansial, dan penganggaran adalah metode atau proses untuk mempersiapkan suatu anggaran. Hal ini dapat disimpulkan bahwa anggaran adalah suatu pokok utama pada kegiatan perusahaan dalam bentuk finansial. Penyusunan anggaran dilakukan agar tujuan ataupun sasaran perusahaan dapat tercapai. Permasalahan dalam penyusunan anggaran yang sering terjadi yaitu kesenjangan anggaran atau disebut juga dengan budgetary slack. Budgetary slack terjadi karena adanya perbedaan total anggaran yang diajukan oleh bawahan 
dengan total estimasi anggaran terbaik. Menurut Young (1985), budgetary slack is defined as the amount by which a subordinate understates his productive capability when given a chance to select a work standard against which his performance will be evaluated.

Faktor yang mempengaruhi budgetary slack dalam penelitian ini yaitu skema kompensasi dan self efficacy. Skema kompensasi adalah suatu cara untuk memotivasi seseorang agar mendapatkan bonus jika target anggaran yang diusulkan dapat tercapai. Hidayah (2016) mengatakan bahwa kompensasi merupakan suatu hal yang diterima bawahan atau karyawan atas jasa yang telah diberikannya pada perusahaan. Kompensasi diberikan perusahaan kepada bawahan agar target anggaran yang ditetapkan dapat tercapai.

Penelitian budgetary slack yang dilakukan oleh Waller (1988) dan Steven (2002) memberikan bukti bahwa tingkat kesenjangan anggaran antara kompensasi truth inducing dan slack inducing memiliki perbedaan. Skema kompensasi truth inducing dapat mengurangi terjadinya budgetary slack dibanding menggunakan skema kompensasi slack inducing. Anggraeni (2016) menyatakan bahwa skema kompensasi menggunakan skema truth inducing membuat penyusun anggaran memikirkan serta mengestimasi supaya kinerja yang dimiliki sesuai dengan target anggaran yang telah diusulkan, sehingga mendapatkan bonus serta terhindar dari denda.

Variabel self efficacy merupakan faktor individual yang mempengaruhi budgetary slack dalam penelitian ini. Menurut Abdullah (2013), self efficacy merupakan suatu kepercayaan atau keyakinan seseorang tentang apakah seseorang tersebut mempunyai kemampuan untuk melakukan suatu tugas tertentu. Self efficacy yang tinggi bisa mengurangi terjadinya budgetary slack yang dilakukan manajer tingkat bawah, sebaliknya self efficacy yang rendah dapat mendorong manajer tingkat bawah untuk melakukan budgetary slack.

Penelitian mengenai skema kompensasi dan self efficacy yang mempengaruhi budgetary slack sampai sekarang masih minim dilakukan. Perbedaan penelitian ini dengan penelitian sebelumnya yaitu adanya faktor individual yaitu self efficacy dan alasan penting lainnya yaitu terdapat perbedaan hasil penelitian. Menurut Efrilna (2018), skema truth inducing menciptakan budgetary slack lebih besar dari pada skema slack inducing, truth inducing membuat participant melakukan slack lebih besar karena tidak ingin mendapatkan penalty. Berbeda dengan penelitian Sampouw (2018) yang menunjukkan bahwa slack inducing dapat mempengaruhi tingkat budgetary slack yang lebih tinggi, sedangkan truth inducing dapat menurunkan tingkat budgetary slack yang rendah. Penelitian Anggraeni (2016) sejalan dengan penelitian Sampouw yaitu kompensasi dengan menggunakan skema slack inducing mempunyai kecenderungan melakukan budgetary slack yang tinggi dibandingkan dengan skema kompensasi truth inducing yang cenderung menghindari budgetary slack.

Penelitian ini diharapkan dapat bermanfaat untuk menekankan terjadinya budgetary slack. Desain penelitian yaitu eksperimen dengan subjek penelitiannya adalah mahasiswa Akuntansi Fakultas Ekonomi Universitas Negeri padang tahun masuk 2016. Penelitian ini menggunakan instrumen tugas produksi dalam bentuk penerjemahan huruf ke dalam angka dengan target yang ditetapkan sendiri (Chong dan Loy, 2015).

Berdasarkan uraian latar belakang di atas mengenai skema kompensasi, self efficacy, dan budgetary slack, maka peneliti tertarik untuk mengambil judul tentang "Pengaruh Skema Kompensasi dan Self Efficacy terhadap Budgetary Slack”. 


\section{REVIU LITERATUR DAN PENGEMBANGAN HIPOTESIS \\ Teori Keagenan}

Budgetary slack didasarkan pada teori keagenan (agency theory). Menurut Jensen dan Meckling (1976) dalam Rahmah dan Sembiring (2014), hubungan agency terjadi ketika satu orang atau lebih pemegang saham (principal) mempekerjakan orang lain (agent) untuk memberikan jasa dan kemudian mendelegasikan wewenang pengambilan keputusan kepada agent tersebut. Teori keagenan ini membahas mengenai konflik kepentingan antara principal dan agent.

Konflik kepentingan diakibatkan oleh adanya pihak yang menginginkan keuntungan yang tinggi agar kesejahteraannya dapat terpenuhi. Agent memiliki tanggung jawab untuk mamaksimalkan keuntungan principal, sedangkan principal memiliki tanggung jawab untuk mengoptimalkan kesejahteraan agent. Kesejahteraan agent ditingkatkan dengan memberikan kompensasi ketika target anggaran dapat dipenuhi oleh agent.

\section{Theory Planned Behavior (TPB)}

Theory planned behavior (TPB) memiliki faktor utama yaitu suatu niat individu atau seseorang untuk melakukan suatu tindakan tertentu (Ajzen,1991). Perilaku niat individu dibentuk menjadi tiga variabel yaitu: variabel sikap, variabel norma subyektif, dan variabel kontrol perilaku yang dirasakan (Fatmawati, 2018: 2). Menurut Prabandari dan Sholihah (2014), TPB dapat membantu baik dalam mengubah maupun memprediksi perilaku individu, sehingga teori TPB ini digunakan untuk menentukan suatu minat atau keinginan seseorang dalam melakukan perilaku atau tindakan tertentu.

\section{Budgetary Slack}

Kesenjangan anggaran atau sering juga disebut dengan Budgetary slack terjadi karena adanya perbedaan total anggaran yang diajukan oleh bawahan dengan total estimasi anggaran terbaik. Menurut Young (1985), budgetary slack is defined as the amount by which a subordinate understates his productive capability when given a chance to select a work standard against which his performance will be evaluated. Hal tersebut disebabkan oleh manajer tingkat bawah yang cenderung membuat anggaran secara tidak wajar agar dapat mencapai target, sehingga manajer tingkat bawah mendapatkan kompensasi/bonus yang tinggi.

\section{Skema Kompensasi}

Atasan atau manajer tingkat atas mempertimbangkan skema kompensasi yang digunakan, hal ini karena manajer tingkat bawah memiliki kebutuhan nilai kompensasi yang berbeda-beda. Anggraeni (2016) menunjukkan bahwa skema kompensasi terbagi menjadi dua, yaitu truth inducing dan slack inducing. Skema kompensasi truth inducing merupakan skema pembayaran kompensasi yang dihitung dengan jumlah gaji dan bonus yang diterima sesuai target anggaran. Manajer tingkat bawah akan menerima bonus jika hasil kinerja sama dengan target anggaran, sebaliknya jika kurang atau melebihi target maka akan dikenakan denda. Skema kompensasi slack inducing adalah skema yang dihitung berdasarkan gaji tetap ditambah dengan bonus jika dapat melebihi target yang telah ditetapkan dan tidak dikenakan denda.

\section{Self Efficacy}

Albert Bandura (1995 : 2) dalam Abdullah (2013) menyatakan bahwa self efficacy adalah suatu kepercayaan terhadap kemapuan seseorang atau individu dalam mengatur dan melaksanakan perilaku tertentu untuk melihat situasi yang akan terjadi di masa depan. Teori self efficacy ini 
berhubungan mengenai apakah seseorang tersebut memiliki kemampuan untuk melakukan suatu tindakan tertentu.

\section{Skema Kompensasi dan Budgetary Slack}

Teori keagenan didasarkan karena adanya konflik kepentingan antara principal dan agent. Konflik ini disebabkan oleh pihak principal bertanggungjawab meningkatkan kesejahteraan agent ketika pihak agent mencapai target anggaran yang ditetapkan, sedangkan pihak agent akan berusaha untuk memaksimalkan keuntungan dalam memenuhi kesejahteraanya. Kepentingan yang berbeda ini yang dapat menyebabkan terjadinya budgetary slack, hal tersebut terjadi karena pihak agent ingin mendapatkan kompensasi yang tinggi dengan memberikan informasi yang bias supaya anggaran dapat tercapai. Kompensasi digunakan agar dapat memotivasi manajer tingkat bawah, sehingga manajer tingkat bawah dapat meningkatkan prestasi kinerjanya dan tujuan perusahaan tercapai. Hal ini dapat dikatakan bahwa kompensasi berpengaruh terhadap budgetary slack.

Sampouw (2018) dan Anggraeni (2016) dalam penelitiannya menyatakan bahwa skema kompensasi truth inducing dan slack inducing berpengaruh terhadap budgetary slack, skema slack inducing berpengaruh terhadap peningkatan budgetary slack yang tinggi, sedangkan truth inducing berpengaruh terhadap penurunan budgetary slack yang lebih rendah. Berdasarkan penjelasan di atas, maka hipotesis pertama yang akan di uji adalah sebagai berikut:

H1: Manajer tingkat bawah yang diberikan kompensasi dengan skema kompensasi slack inducing akan cenderung melakukan budgetary slack dibanding manajer tingkat bawah yang diberikan kompensasi dengan skema truth inducing yang cenderung menghindari budgetary slack.

\section{Self Efficacy dan Budgetary Slack}

Konsep penelitian self efficacy berdasarkan theory planned behavior (TPB). Menurut Prabandari dan Sholihah (2014), TPB dapat membantu baik dalam mengubah maupun memprediksi perilaku individu, sehingga teori TPB ini digunakan untuk menentukan suatu minat atau keinginan seseorang dalam melakukan perilaku atau tindakan tertentu. TPB dan self efficacy sama-sama berhubungan dengan keyakinan seseorang mengenai apakah seseorang tersebut memiliki kemampuan untuk melakukan suatu tindakan tertentu. Self efficacy tinggi yang dimiliki oleh seseorang akan bisa untuk mencapai kinerja yang baik, hal ini dikarenakan adanya pemikiran yang positif, sedangkan self efficacy yang rendah kurang mampu dalam mencapai hasil yang baik, hal ini dikarenakan adanya pemikiranyang negatif. Hal ini dapat menyebabkan terjadinya budgetary slack.

Abdullah (2013) menyatakan bahwa self efficacy tinggi akan cenderung dapat mengurangi terjadinya budgetary slack karena manajer tingkat bawah cenderung mampu mencapai target, sedangkan self efficacy rendah cenderung akan lebih meningkatkan terjadinya budgetary slack karena kurang mampu atau tidak mampu untuk mencapai target, sehingga ia melakukan budgetary slack agar target anggarannya dapat tercapai. Penjelasan tersebut dapat disimpulkan bahwa hipotesis dua sebagai berikut:

H2: Manajer tingkat bawah dengan self efficacy tinggi lebih cenderung melakukan budgetary slack lebih rendah dibanding manajer tingkat bawah dengan self efficacy rendah. 


\section{Skema Kompensasi dan Self Efficacy terhadap Budgetary Slack}

Skema kompensasi terdiri dari dua yaitu skema truth inducing dan skema slack inducing. Skema kompensasi truth inducing dihitung dengan jumlah gaji dan bonus yang diterima sesuai target anggaran. Manajer tingkat bawah akan menerima bonus jika hasil kinerja sama dengan target anggaran, sebaliknya jika kurang atau melebihi target maka akan dikenakan denda. Skema kompensasi slack inducing dihitung berdasarkan gaji tetap ditambah dengan bonus jika dapat melebihi target yang telah ditetapkan dan jika tidak melebihi target maka tidak dikenakan denda.

Hipotesis sebelumnya telah menjelaskan bahwa self efficacy berpengaruh terhadap budgetary slack. Self efficacy tinggi akan cenderung dapat mengurangi terjadinya budgetary slack karena manajer tingkat bawah cenderung mampu mencapai target, sedangkan self efficacy rendah cenderung akan lebih meningkatkan terjadinya budgetary slack karena kurang mampu atau tidak mampu untuk mencapai target, sehingga ia melakukan budgetary slack agar target anggarannya dapat tercapai.

Manajer tingkat bawah yang memiliki self efficacy rendah dengan menggunakan skema slack inducing akan melakukan budgetary slack lebih tinggi karena tidak merasa mampu untuk mencapai target anggaran yang telah ditetapkan, sehingga manajer tingkat bawah melakukan budgetary slack agar dapat mencapai target serta mendapatkan bonus yang tinggi. Berdasarkan penjelasan diatas dapat ditarik hipotesis tiga, yaitu:

H3: Manajer tingkat bawah yang memiliki self efficacy rendah dalam skema kompensasi slack inducing akan cenderung melakukan budgetary slack dibanding manajer tingkat bawah yang memiliki self efficacy rendah dalam skema kompensasi truth inducing.

\section{METODE PENELITIAN \\ Desain Penelitian}

Penelitian ini menggunakan pendekatan kuantitatif dengan jenis penelitian kausatif, dan penelitian ini menggunakan data primer yang dikumpulkan dengan metode yang ada dalam jenis penelitian kuasi eksperimen. Subjek penelitian ini adalah mahasiswa jurusan Akuntansi Fakultas Ekonomi Universitas Negeri Padang tahun masuk 2016. Penelitian ini menggunakan total sampling dengan jumlah sampel sebanyak 107 orang mahasiswa. Mahasiswa tahun masuk 2016 diambil karena masih dalam proses perkuliahan dan sudah mengambil mata kuliah anggaran perusahaan dan akuntansi manajemen. Hal tersebut dapat dikatakan bahwa mahasiswa telah memiliki pengetahuan yang cukup tentang penyusunan anggaran ataupun permasalahan yang sering terjadi dalam penyusunan anggaran.

Desain kuasi eksperimen dalam penelitian ini adalah menggunakan faktorial $2 \times 2$, hal ini karena variabel bebas penelitian ini terdiri dari skema kompensasi yang terdiri dari truth inducing dan slack inducing, serta variabel bebas kedua yaitu self efficacy yang terdiri dari self efficacy rendah dan self efficacy tinggi. (Desain faktorial 2x2 terlampir).

\section{Teknik Pengumpulan Data}

Teknik pengumpulan data penelitian ini yaitu dengan membagikan kertas kerja decoding dalam bentuk penerjemahan huruf ke dalam angka. Waktu pembagian kertas kerja sesuai dengan jadwal kuliah partisipan, hal tersebut agar tercapainya tingkat pengembalian kertas kerja yang tinggi. Kelompok perlakuan ditentukan secara acak (random). 


\section{Prosedur Penelitian}

Tahapan prosedur penelitian ini mengikuti tahapan prosedur yang dilakukan oleh Efrilna (2018), yaitu sebagai berikut:

a. Membagikan kertas kerja "penerjemahan huruf ke dalam angka" kepada partisipan.

b. Peneliti menjelaskan cara mengerjakan kertas kerja kepada partisipan dalam waktu kurang lebih 5 menit.

c. Pengisian identitas pribadi partisipan.

d. Sesi belajar, partisipan melakukan percobaan "terjemahan huruf ke dalam angka" selama 1 menit.

e. Sesi latihan, partisipan diminta untuk mengerjakan "terjemahan huruf ke dalam angka" selama 2 menit.

f. Partisipan diminta untuk mengisi target yang ingin dicapai untuk sesi tugas kerja selanjutnya.

g. Sesi kerja, partisipan diminta untuk mngerjakan "terjemahan huruf ke dalam angka" selama 2 menit sesuai dengan target yang telah ditetapkan sebelumnya.

h. Pengisian manipulation check.

\section{Pengukuran Variabel}

\section{a. Budgetary Slack (Y)}

Variabel budgetary slack diukur dengan menggunakan rumus Steven (2002), yaitu sebagai berikut:

$$
\begin{aligned}
& \text { Budgetary Slack }=\frac{\text { Hasil Sesi Kerja-Target Tugas }}{\text { Expected Performance }} \\
& \text { Expected Performance }=\frac{\text { Hasil Sesi Belajar }+ \text { Hasil Sesi Latihan }}{2}
\end{aligned}
$$

\section{b. Skema Kompensasi (X1)}

Skema kompensasi dibagi menjadi dua kelompok kasus, kelompok pertama yaitu truth inducing. Rumus truth inducing mengikuti rumus yang dipakai oleh Sampouw (2018) dan Anggraeni (2016), yaitu sebagai berikut:

$$
\begin{array}{ll}
\mathrm{P}=\operatorname{Rp} 10.000+(\operatorname{Rp} 1.000 \times \mathrm{A}) \quad & \text { jika } \mathrm{A}=\mathrm{B} \\
\mathrm{P}=\operatorname{Rp} 10.000-\{\operatorname{Rp} 1.000 \times(\mathrm{A}-\mathrm{B})\} & \text { jika } \mathrm{A}>\mathrm{B} \\
\mathrm{P}=\operatorname{Rp} 10.000-\{\operatorname{Rp} 1.000 \times(\mathrm{B}-\mathrm{A})\} & \text { jika } \mathrm{A}<\mathrm{B}
\end{array}
$$

$$
\begin{array}{ll}
\text { Keterangan: } & \\
\mathrm{P} & =\text { Total kompensasi yang diterima oleh bawahan } \\
\mathrm{A} & =\text { Hasil kerja sesungguhnya } \\
\mathrm{B} & =\text { Target kerja yang ditetapkan } \\
\text { Gaji tetap } & =\mathrm{Rp} 10.000 \\
\text { Bonus } & =\mathrm{Rp} 1.000 \\
\text { Punishment } & =\mathrm{Rp} 1.000
\end{array}
$$

Kelompok kedua adalah slack inducing. Rumus skema kompensasi slack inducing mengikuti rumus Sampouw (2018), Efrilna (2018), Anggraeni (2016), dan Chong and Loy (2015) yaitu sebagai berikut: 


$$
\begin{array}{ll}
\mathrm{P}=\operatorname{Rp} 10.000 & \text { Jika } \mathrm{A} \leq \mathrm{B} \\
\mathrm{P}=\operatorname{Rp} 10.000+\{\operatorname{Rp} 1.000 \times(\mathrm{A}-\mathrm{B})\} & \text { Jika } \mathrm{A}>\mathrm{B}
\end{array}
$$

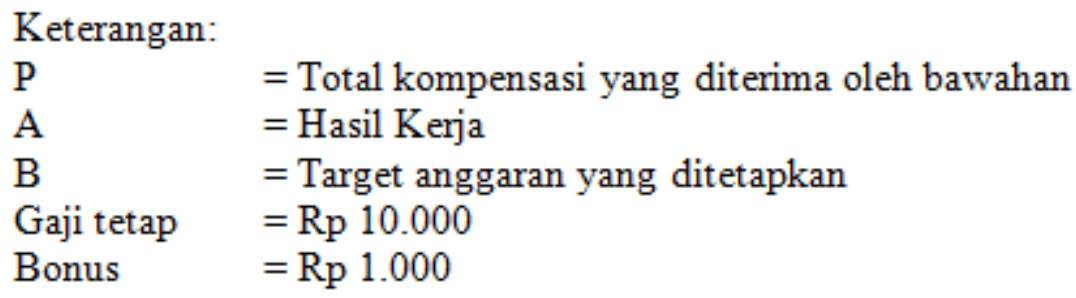

c. Self Efficacy

Pengaruh self efficacy terhadap budgetary slack dimanipulasi dengan dua kelompok perlakuan yaitu self efficacy tinggi dan self efficacy rendah. Berdasarkan pengertian self efficacy maupun teori self efficacy, maka kelompok pertama yaitu partisipan yang targetnya lebih tinggi dari sesi latihan dikelompokkan menjadi self efficacy tinggi, dan kelompok dua partisipan yang targetnya lebih rendah dari sesi latihan maka dikelompokkan menjadi self efficacy rendah. Penelitian self efficacy menggunakan pengukuran yang digunakan oleh Ardiyani (2017) yaitu variabel dummy. Peneliti memberikan angka 0 untuk kondisi self efficacy rendah dan angka 1 untuk self efficacy tinggi.

\section{HASIL DAN PEMBAHASAN Manipulation Check}

Partisipan diminta untuk menjawab pernyataan manipulation check untuk mengetahui pemahaman partisipan terkait dengan kasus kelompok perlakuan yang diberikan. Partisipan yang lolos manipulation check akan digunakan untuk mengolah data lebih lanjut, sedangkan partisipan yang tidak lolos manipulation check tidak digunakan untuk mengolah data lebih lanjut. Hal ini dikarenakan partisipan yang tidak lolos manipulation check dianggap tidak memahami kasus kelompok perlakuan yang diberikan, sehingga akan mempengaruhi respon partisipan tersebut.

Partisipan yang lolos manipulation check jika dapat menjawab dua pernyataan dengan benar dan sesuai dengan kasus yang diberikan. Partisipan diminta untuk memberikan respon benar atau salah sesuai dengan pernyataan yang peneliti berikan. Pernyataan yang diberikan tersebut berkaitan dengan kasus kelompok perlakuan yang peneliti berikan.

\section{Uji Asumsi dan Hipotesis}

\section{a. Uji Normalitas dan Homogenitas}

Uji normalitas menggunakan uji Kolmogorov Smirnov, yaitu jika nilai signifikansi $>0,05$ maka dapat disimpulkan bahwa data tersebut berdistribusi normal, sedangkan jika nilai signifikansi < 0,05 maka disimpulkan bahwa data tersebut tidak berdistribusi normal. Variabel budgetary slack (Y) mempunyai signifikansi sebesar 0,016. (Hasil uji normalitas terlampir). Data penelitian ini tidak berdistribusi normal, sehingga uji beda dalam penelitian ini menggunakan uji mannwhitney. Menurut Suyanto dan Gio (2017:19), uji mann-whitney merupakan alternatif dari uji t untuk dua populasi independen ketika asumsi normalitas populasi tidak terpenuhi.

Pengujian homogenitas dapat dilakukan dengan cara uji Levene's Test. Kriteria pengujian homogenitas, jika nilai signifikansi > 0,05 maka dapat dikatakan bahwa varian dua atau lebih kelompok data adalah homogen (Puspita dan Lubis, 2017). Hasil uji homogenitas dapat dilihat pada tabel 3 bahwa nilai signifikansi sebesar 0,400 yang berarti >0,05. Hal tersebut dapat 
disimpulkan bahwa data penelitian ini memiliki varian yang sama secara signifikan atau homogen, sehingga syarat asumsi terpenuhi. (Hasil uji homogenitas terlampir)

\section{b. Uji Two Ways ANOVA}

Two ways anova digunakan karena ada dua atau lebih variabel independent. Uji ini digunakan untuk mengetahui perbedaan signifikan antara kedua variabel independent. Uji two ways anova dilakukan dengan menggunakan metode post hoc dengan teknik Tukey. Jika hasil uji $\leq 0,05$ maka terdapat perbedaan yang signifikan pada variabel independent, sehingga dapat menunjukkan bahwa variabel tersebut berpengaruh terhadap variabel dependent (Efrina, 2018).

\section{c. Uji Beda}

Uji beda digunakan untuk mengetahui nilai rata-rata perbedaan variasi antara dua kelompok data. Uji beda untuk pengujian nilai rata-rata kelompok daya independent dilakukan dengan menggunakan mann-whitney. Nilai signifikansi $\leq 0,05$ dapat disimpulkan bahwa terdapat perbedaan nilai rata-rata dua kelompok data yang independent tersebut (Irianto, 2010) dalam Efrilna (2018).

\section{Deskriptif Data Penelitian}

Berdasarkan data check manipulation serta yang lulus mata kuliah anggaran perusahaan dan akuntansi manajemen, data yang dapat diolah adalah sebanyak 83. Partisipan yang tidak lolos check manipulation sebanyak 11 orang, hal ini disebabkan karena responden kemungkinan kurang memahami kelompok perlakuan yang peneliti berikan, serta sebagian besar dari 11 orang tersebut menjawab pertanyaan manipulation check tidak berdasarkan situasi atau perlakuan yang dihadapi, tapi berdasarkan pilihan yang terbaik mereka. Partisipan tidak lulus mata kuliah anggaran perusahaan dan akuntansi manajemen adalah sebanyak 2 orang, sehingga dapat disimpulkan response rate penyebaran kertas kerja adalah 86,46\% atau 83 orang partisipan. Responden sebagian besar berasal dari jenis kelamin perempuan dengan total persentase $71,1 \%$ atau 59 orang partisipan. Responden laki-laki berjumlah $28,9 \%$ atau 24 orang partisipan dalam penelitian ini.

\section{Uji Hipotesis}

\section{a. Hipotesis Pertama}

Hipotesis pertama ini menggunakan uji two ways ANOVA. Rumusan hipotesis pertama (H1) yaitu manajer tingkat bawah yang diberikan kompensasi dengan skema kompensasi slack inducing akan cenderung melakukan budgetary slack dibanding manajer tingkat bawah yang diberikan kompensasi dengan skema truth inducing yang cenderung menghindari budgetary slack.

Hasil uji hipotesis menunjukkan mean square senilai 2,69 yang diperkuat dengan signifikansi uji analisis two ways ANOVA yaitu sebesar $0,00<0,05$. Hal tersebut membuktikan manajer tingkat bawah yang diberikan kompensasi dengan skema kompensasi slack inducing akan cenderung melakukan budgetary slack dibanding manajer tingkat bawah yang diberikan kompensasi dengan skema truth inducing yang cenderung menghindari budgetary slack adalah benar. (Hasil uji hipotesis terlampir).

Hipotesis pertama memiliki tambahan uji yaitu uji non-parametrik. Uji non-parametrik ini bertujuan untuk kelengkapan hasil penelitian yang yang memiliki data yang tidak berdistribusi normal. Pengujian non-parametrik yang digunakan yaitu mann-whitney yang 
bertujuan untuk mengetahui adanya perbedaan dua kelompok dengan skala ordinal ataupun interval.

Hasil uji mann-whitney menunjukkan mean rank pada skema kompensasi truth inducing dan skema kompensasi slack inducing yang berbeda yaitu berturut-turut sebesar 26,54 dan 57,10, serta diperkuat oleh nilai $p$ value yang ditunjukkan dengan aymp. sig. yang memiliki hasil 0,00. Nilai $p$ value sebesar 0,00 yang kurang dari batasnya yaitu 0,05 yang berarti $\mathrm{H} 1$ diterima atau skema kompensasi memberikan pengaruh bermakna terhadap budgetary slack. Hasil kesimpulannya yaitu hipotesis pertama (H1) diterima. (Hasil uji mann whitney terlampir).

\section{b. Hipotesis Kedua}

Uji hipotesis kedua di penelitian ini yaitu dengan menggunakan uji two ways ANOVA. Hipotesis kedua (H2) dirumuskan dengan manajer tingkat bawah dengan self efficacy tinggi lebih cenderung melakukan budgetary slack lebih rendah dibanding manajer tingkat bawah dengan self efficacy rendah.

Hasil uji hipotesis menunjukkan bahwa mean square sebesar 1,311 dan diperkuat oleh analisis two ways ANOVA dengan signifikansi $0,00<0,05$. Hal tersebut membuktikan adanya perbedaan antara perlakuan individu yang memiliki self efficacy rendah dengan self efficacy tinggi terhadap budgetary slack.

Hipotesis dua ini memiliki uji non-parametrik. Uji ini bertujuan untuk kelengkapan hasil penelitian yang yang memiliki data yang tidak berdistribusi normal. Pengujian non-parametrik yang digunakan yaitu mann-whitney yang bertujuan untuk mengetahui adanya perbedaan dua kelompok dengan skala ordinal ataupun interval.

Hasil uji mann-whitney dapat dilihat bahwa mean rank pada self efficacy rendah dan self efficacy tinggi memiliki perbedaan yaitu memiliki nilai 61,27 dan 34,16 serta diperkuat oleh signifikansi dengan hasil sebesar 0,00. Hal ini menunjukkan nilai $p$ value sebesar $0,00<0,05$ yang berarti dapat menerima $\mathrm{H} 2$ atau self efficacy memiliki pengaruh bermakna terhadap budgetary slack. Hasil ini dapat disimpulkan bahwa hipotesis kedua (H2) diterima.

\section{c. Hipotesis Ketiga}

Pengujian pada hipotesis ketiga ini diuji dengan menggunakan analisis two ways ANOVA. Hipotesis ketiga yang dirumuskan pada penelitian ini yaitu manajer tingkat bawah yang memiliki self efficacy rendah dalam skema kompensasi slack inducing akan cenderung melakukan budgetary slack dibanding manajer tingkat bawah dengan self efficacy rendah dalam skema kompensasi truth inducing.

Hasil uji hipotesis menunjukkan bahwa mean square sebesar 0,388 dan diperkuat oleh nilai signifikansi uji analisis two ways ANOVA sebesar 0,048 $<0,05$. Hal tersebut dapat membuktikan bahwa adanya pengaruh interaksi skema kompensasi dan self efficacy terhadap budgetary slack.

Hasil uji mann-whitney menunjukkan bahwa mean rank tertinggi pada skema kompensasi yaitu slack inducing sebesar 57,10. Mean rank pada self efficacy yang paling tinggi adalah self efficacy rendah yaitu sebesar 61,27. Hal ini dapat membuktikan bahwa budgetary slack terjadi pada manajer tingkat bawah yang memiliki self efficacy rendah dalam skema kompensasi slack inducing. 


\section{Analisis Tambahan}

Berdasarkan tabel 6, perbandingan nilai rata-rata kelompok eksperimen memiliki nilai tertinggi yang terdapat pada self efficacy rendah dalam skema kompensasi slack inducing yaitu sebesar 0,6783. Rata-rata nilai terendah terdapat pada self efficacy tinggi dalam skema kompensasi truth inducing dengan rata-rata $-0,0746$. Hasil tersebut menunjukkan bahwa manajer tingkat bawah yang memiliki self efficacy rendah dalam skema kompensasi slack inducing akan melakukan budgetary slack lebih besar dibanding manajer tingkat bawah yang memiliki self efficacy rendah dalam skema kompensasi truth inducing. Manajer tingkat atas yang menggunakan skema kompensasi truth inducing akan melakukan budgetary slack yang lebih kecil. Hasil tersebut dapat disimpulkan bawah hipotesis ketiga (H3) diterima. (Hasil perbandingan nilai rata-rata kelompok eksperimen terlampir)

\section{Pembahasan}

\section{Perbedaan Pengaruh Skema Kompensasi terhadap Budgetary Slack}

Hasil uji hipotesis dapat menunjukkan perbedaan pengaruh skema kompensasi truth inducing dan slack inducing. Hal ini dapat dilihat dari hasil pengolahan data menggunakan uji two ways ANOVA. Hasil tabel menunjukkan tabel $\mathrm{F}$ hitung sebesar 27,997 dan juga diperkuat oleh nilai signifikansi sebesar $0,00<0,05$. Hasil penelitian ini sesuai dengan teori keagenan yang menjelaskan adanya konflik kepentingan antara manajer tingkat atas dengan manajer tingkat bawah. Manajer tingkat atas bertanggungjawab untuk meningkatkan kesejahteraan manajer tingkat bawah jika manajer tingkat bawah memenuhi target yang dianggarkan, sedangkan manajer tingkat bawah berusaha memaksimalkan keuntungan untuk memenuhi kesejahteraannya. Hal ini yang menyebabkan terjadinya budgetary slack, karena manajer tingkat bawah berusaha merendahkan target anggaran agar dapat mencapai angka yang tinggi, sehingga dengan target yang rendah dan mencapai angka target yang lebih tinggi maka kompensasi yang didapatkan juga akan tinggi.

Skema slack inducing yang menyebabkan slack ini karena memiliki peluang dan tidak ada punishment, sehingga manajer tingkat bawah termotivasi untuk meninggikan kompensasi dengan membuat target anggaran yang rendah daripada membuat target anggaran yang sesuai dengan kemampuannya atau yang sebenarnya. Manajer tingkat bawah dengan skema kompensasi truth inducing akan cenderung melakukan budgetary slack lebih rendah karena memiliki tekanan dari atasan, seperti jika kurang atau melampaui target maka akan dikenakan punishment berupa pengurangan gaji pokok. Berdasarkan penjelasan tersebut dapat dikatakan bahwa skema kompensasi slack inducing akan cenderung melakukan budgetary slack lebih tinggi dibanding menggunakan skema kompensasi truth inducing.

Hasil penelitian ini sejalan dengan penelitian Anggraeni (2016) dan Sampouw (2018) dalam penelitiannya menyatakan bahwa skema kompensasi truth inducing dan slack inducing berpengaruh terhadap budgetary slack, skema slack inducing berpengaruh terhadap peningkatan bugetary slack yang tinggi, sedangkan truth inducing berpengaruh terhadap penurunan budgetary slack yang lebih rendah. Penelitian ini tidak sejalan dengan penelitian Stevens (2002) yang menyatakan bahwa kompensasi melalui slack inducing berpengaruh negatif terhadap budgetary slack.

\section{Perbedaan Pengaruh Self Efficacy terhadap Budgetary Slack}

Hasil uji hipotesis membuktikan bahwa perbedaan self efficacy tinggi dan rendah berpengaruh signifikan terhadap budgetary slack. Hal tersebut dapat dilihat dari hasil pengolahan data dengan 
menggunakan uji two ways ANOVA. Hasil tabel F hitung menunjukkan angka 13,652 dan nilai signifikansi sebesar $0,00<0,05$. Hasil penelitian ini dapat disimpulkan bahwa adanya perbedaan antara self efficacy tinggi dan rendah yang mempengaruhi budgetary slack. Hal ini sesuai dengan theory planned behavior yang merupakan faktor utama dalam menentukan minat/keinginan individu untuk melakukan perilaku tertentu. TPB secara khusus menghubungkan belief (kepercayaan) dengan attitudes, sedangkan self efficacy juga berhubungan dengan keyakinan seseorang tentang apakah ia memiliki kemampuan untuk melakukan tindakan tertentu. Self efficacy tinggi yang dimiliki seseorang akan lebih mampu untuk mencapai kinerja yang lebih baik, karena memiliki pikiran yang positif, motivasi yang kuat, dan tujuan yang jelas sehingga dapat meyakinkan kemampuan dirinya dalam melakukan pekerjaan. Individu yang memiliki self efficacy yang rendah cenderung kurang mampu dalam menjalan tugas karena adanya pikiran negatif dalam pikirannya seperti kegagalan serta kurang percaya diri dengan kemampuan yang dimilikinya, sehingga hal ini dapat mendorong terjadinya penyusunan anggaran yang bias dan menyebabkan terjadinya budgetary slack.

Hasil penelitian ini konsisten dengan penelitian yang dilakukan oleh Abdullah (2013) mengenai "the influence of horizontal equity, self efficacy, and ethical position on the creation of budgetary slack" menunjukkan bahwa self efficacy berpengaruh terhadap budgetary slack. Penelitian ini tidak sejalan dengan penelitian Ardiyani (2017) dan Fanani dan Saudale (2018) yang menyatakan bahwa self efficacy tidak berpengaruh terhadap budgetary slack.

\section{Pengaruh Interaksi Skema Kompensasi dan Self Efficacy terhadap Budgetary Slack}

Berdasarkan hasil uji hipotesis tiga dapat diketahui bahwa self efficacy yang rendah dalam skema kompensasi slack inducing memiliki signifikansi $<0,05$. Nilai signifikansi adalah sebesar 0,048 dan F hitung sebesar 4,037. Hal tersebut menunjukkan bahwa terdapat pengaruh interaksi orang yang memiliki self efficcay rendah dalam skema slack inducing terhadap budgetary slack yang memiliki makna hipotesis tiga diterima.

Manajer tingkat bawah yang memiliki self efficacy rendah dengan menggunakan skema slack inducing akan merasa tidak mampu untuk mencapai target anggaran. Hal ini akan lebih cenderung melakukan budgetary slack agar target anggarannya mudah tercapai pada tingkat yang tinggi, serta mendapatkan bonus/kompensasi yang tinggi. Hasil perbandingan nilai rata-rata kelompok eksperimen dapat dilihat pada tabel 6 yang menunjukkan bahwa nilai tertinggi terdapat pada self efficacy rendah dalam skema kompensasi slack inducing yaitu sebesar 0,6783. Rata-rata nilai terendah terdapat pada self efficacy tinggi dalam skema kompensasi truth inducing dengan rata-rata $-0,0746$. Hasil tersebut menunjukkan bahwa manajer tingkat bawah yang memiliki self efficacy rendah dalam skema kompensasi slack inducing akan melakukan budgetary slack lebih besar dibanding manajer tingkat bawah yang memiliki self efficacy rendah dalam skema kompensasi truth inducing.

\section{SIMPULAN, KETERBATASAN, DAN SARAN \\ Kesimpulan}

Hasil penelitian dan pengujian hipotesis ini telah dilakukan, maka hasil penelitian dapat disimpulkan sebagai berikut (1) manajer tingkat bawah yang diberikan kompensasi dengan skema kompensasi slack inducing akan cenderung melakukan budgetary slack dibanding manajer tingkat bawah yang diberikan kompensasi dengan skema kompensasi truth inducing yang cenderung menghindari budgetary slack, (2) manajer tingkat bawah dengan self efficacy tinggi lebih cenderung melakukan budgetary slack lebih rendah dibanding manajer tingkat 
bawah dengan self efficacy rendah, (3) manajer tingkat bawah yang memiliki self efficacy rendah dalam skema kompensasi slack inducing akan cenderung melakukan budgetary slack dibanding manajer tingkat bawah yang memiliki self efficacy rendah dalam skema kompensasi truth inducing, (4) perbandingan nilai rata-rata kelompok eksperimen memiliki nilai tertinggi pada self efficacy rendah dalam skema kompensasi slack inducing yaitu sebesar 0,6783.

\section{Keterbatasan}

Penelitian ini memiliki keterbatasan yaitu sebagai berikut (1) partisipan penelitian ini sebagian kecil masih kurang bisa memahami prosedur penelitian dan perlakuan yang diberikan, sehingga masih ada yang tidak lolos cek manipulasi, (2) populasi penelitian juga masih sebatas mahasiswa akuntansi S1 Fakultas Ekonomi Universitas Negeri Padang tahun masuk 2016.

\section{Saran}

Berdasrkan keterbatasan di atas, maka peneliti selanjutnya diharapkan (1) memberikan perlakuan/treatment terhadap partisipan secara lebih baik, sehingga partisipan dapat memahami petunjuk dan lolos dalam cek manipulasi, (2) menambah populasi penelitian agar hasilnya lebih generalisasi, (3) menggunakan variabel lain yang mempengaruhi budgetary slack.

\section{DAFTAR PUSTAKA}

Abdullah, I. (2013). The Influence of Horizontal Equity, Self Efficacy, and Ethical Position on the Creation of Budgetary Slack. Disertasi. Virginia Commonwealth University.

Ajzen, I. (1991). The Theory of Planned Behavior. Organizational Behavior and Human Decision Processes, 179-211.

Anggraeni, A. (2016). Pengaruh Self Esteem, Etika, Skema Kompensasi Slack Inducing dan Truth Inducing serta Asimetri Informasi terhadap Budgetary Slack: Study Eksperimen pada Konteks penganggaran Partisipatif. Skripsi. Fakultas Ekonomi Universitas Negeri

Yogyakarta.

Ardiyani, F., \& Sukirno. (2017). Pengaruh Self Efficacy, Reward and Punishment, dan Asimetri Informasi terhadap Budgetary Slack: Studi Eksperimen pada Konteks Penganggaran Partisipatif. Jurnal Nominal , Vol. 6 No.1 : 66-80.

Chong, V. K., \& Loy, C. Y. (2015). The Effect of A Leader's Reputation on Budgetary Slack. Advances in Management Accounting, Vol. 25 : 49-102.

Efrilna, P. (2018). Pengaruh Skema Pemberian Insentif dan Tanggung Jawab Personal terhadap Budgetary Slack. Fakultas Ekonomi Universitas Negeri Padang .

Falikhatun. (2007). Interaksi Asimetri Informasi, Budaya Organisasi, dan Group Cohesiveness

dalam Hubungan antara Partisipasi Penganggaran dan Budgetary Slack (Studi Kasus pada Rumah Sakit Umum Daerah se-Jawa Tengah. Simposium Nasional Akuntansi (SNA) X, Makassar (26-27 Juli 2007).

Fanani, Z., \& Saudale, G. E. (2018). Influence of Information Asymmetry and Self-Efficacy on Budgetary Slack: An Experimental Study. Jurnal Akuntansi dan Keuangan , Vol. 20 No. $2: 62-72$.

Fatmawati, I. (2018). The 4th International Conference on Management Sciences (ICoMS) 2018. Yogyakarta: Universitas Muhammadiyah Yogyakarta. http://repository.umy.ac.id/. 
Hidayah, N. (2016). Pengaruh Kompensasi terhadap Kinerja Karyawan Melalui Kepuasan Kerja sebagai Variabel Intervening. Fakultas Ekonomi Universitas Negeri Yogyakarta. Mardiasmo. (2002). Akuntansi Sektor Publik (IV ed.). Yogyakarta: Andi Yogyakarta.

Prabandari, S. P., \& Sholihah, P. I. (2014). The Influence of Theory of Planned Behavior and Entrepreneurship Education Towards Entrepreneurial Intention. Journal of Economics, Business, and Accountancy Ventura, Vol. 17 No. 3 : 385-392.

Puspita, L. M., \& Lubis, I. R. (2017). Pengaruh Reputasi Pemimpin terhadap Budgetary Slack dengan Kejujuran sebagai Variabel Intervening: Sebuah Eksperimen. Simposium Nasional Akuntansi (SNA) XX, Jember 1-14.

Rahmah, N. A., \& Sembiring, F. M. (2014). Suatu Tinjauan Teori Keagenan: Asimetri Informasi dalam Praktik Manajemen Laba. Jurnal Proceedings SNEB , Hal. 2.

Rifqi, R. A., Subekti, I., \& Rahman, A. F. (2017). The Effect of Budgetary Participation to Budgetary Slack With External Pressure As Moderating Variable. Journal of Accounting and Business Education .

Sampouw, C. E. (2018). Experimental Study: The Influence of Pay Scheme and Personal Value to Budgetary Slack. Journal of Applied Management, Vol. 16 No. $4: 614-\quad 621$.

Stevens, D. E. (2002). The Effects of Reputation and Ethics on Budgetary Slack. Journal of Management Accounting Research, 153-171.

Suyanto, \& Gio, P. U. (2017). Statistika Nonparametrik dengan SPSS, Minitab, dan $R$ : Dilengkapi dengan Penyelesaian Perhitungan Secara Manual. Medan: USU Press. https://www. e-book+uji+non+parametrik.

Waller, W. S. (1988). Slack in Participative Budgeting: The Join Effect of A Truth-Inducing Pay Scheme and Risk Preferences. Accounting, Organizations, and Society, Vol. 13 No. $1: 87-98$.

Young, S. M. (1985). Participative Budgeting: The Effects of Risk Aversion and Asymmetric Information On Budgetary Slack. Journal of Accounting Research , 829- 842. 


\section{LAMPIRAN}

Tabel 1

Desain Faktorial 2 × 2

\begin{tabular}{|c|c|c|c|}
\hline \multicolumn{2}{|c|}{} & \multicolumn{2}{|c|}{ Skema Kompensasi } \\
\cline { 3 - 4 } & Truth Inducing & Slack Inducing \\
\hline \multirow{2}{*}{ Self Efficacy } & Tinggi & BS1 & BS2 \\
\cline { 2 - 4 } & Rendah & BS3 & BS4 \\
\hline
\end{tabular}

Keterangan:

BS1 : Budgetary slack dengan perlakuan truth inducing dan self efficacy tinggi BS2 : Budgetary slack dengan perlakuan slack inducing dan self efficacy tinggi

BS3 : Budgetary slack dengan perlakuan truth inducing dan self efficacy rendah

BS4 : Budgetary slack dengan perlakuan slack inducing dan self efficacy rendah

Tabel 2

Uji Normalitas

One-Sample Kolmogorov-Smirnov Test

\begin{tabular}{|ll|r|}
\hline & & \multicolumn{2}{|c|}{ Budgetary } \\
& & Slack \\
\hline $\mathrm{N}$ & Mean & 83 \\
Normal & .1784 \\
Parameters $^{\mathrm{a}} \quad$ Std. Deviation & .41921 \\
Most Extreme & Absolute & .171 \\
Differences $\quad$ Positive & .171 \\
& Negative & -.167 \\
Kolmogorov-Smirnov Z & 1.556 \\
Asymp. Sig. (2-tailed) & .016 \\
\hline
\end{tabular}

a. Test distribution is Normal.

Sumber: data primer diolah, 2019 
Tabel 3

Uji Homogenitas

\section{Levene's Test of Equality of Error Variances ${ }^{\text {a }}$}

Dependent Variable : Budgetary Slack

\begin{tabular}{|c|c|c|c|}
\hline Levene Statistic & df1 & df2 & Sig. \\
\hline .994 & 3 & 79 & .400 \\
\hline
\end{tabular}

Tests the null hypothesis that the error variance of the dependent variable is equal across groups.

Design: Intercept $+\mathrm{X} 1+\mathrm{X} 2+\mathrm{X} 1 * \mathrm{X} 2$

Sumber: data primer diolah, 2019

Tabel 4

\section{Hasil Uji Hipotesis}

\section{Tests of Between-Subjects Effects}

Dependent Variable:Budgetary Slack

\begin{tabular}{|c|c|c|c|c|c|}
\hline Source & $\begin{array}{c}\text { Type III Sum of } \\
\text { Squares }\end{array}$ & Df & Mean Square & F & Sig. \\
\hline Corrected Model & $6.825^{\mathrm{a}}$ & 3 & 2.275 & 23.695 & .000 \\
Intercept & 2.593 & 1 & 2.593 & 27.007 & .000 \\
X1 & 2.688 & 1 & 2.688 & 27.997 & .000 \\
X2 & 1.311 & 1 & 1.311 & 13.652 & .000 \\
X1 * X2 & .388 & 1 & .388 & 4.037 & .048 \\
Error & 7.585 & 79 & .096 & & \\
Total & 17.053 & 83 & & & \\
Corrected Total & 14.410 & 82 & & & \\
\hline
\end{tabular}

R Squared = ,474 (Adjusted R Squared = ,454)

Sumber: data primer diolah, 2019

Tabel 5

Uji Mann-Whitney

\begin{tabular}{|l|c|c|}
\hline & Mean Rank & \multirow{2}{*}{ Sig. } \\
\hline Skema Kompensasi Truth Inducing & 26,54 & \multirow{2}{*}{0,00} \\
\hline Skema Kompensasi Slack Inducing & 57,10 & \\
\cline { 1 - 2 } Self Efficacy Rendah & 61,27 & \multirow{2}{*}{0,00} \\
\hline Self Efficacy Tinggi & 34,16 & \\
\hline
\end{tabular}

Sumber: data primer diolah, 2019 
Tabel 6

Perbandingan Nilai Rata-Rata antar Kelompok Eksperimen

Dependent Variable:Budgetary Slack

\begin{tabular}{|cc|c|c|c|}
\hline $\begin{array}{c}\text { Skema } \\
\text { Kompensasi }\end{array}$ & Self Efficacy & Mean & Std. Deviation & N \\
\hline \multirow{2}{*}{ Truth Inducing } & Rendah & .0667 & .16330 & 6 \\
& Tinggi & -.0746 & .31754 & 35 \\
& Total & -.0539 & .30265 & 41 \\
\hline \multirow{2}{*}{ Slack Inducing } & Rendah & .6783 & .34504 & 18 \\
& Tinggi & .2004 & .29486 & 24 \\
& Total & .4052 & .39425 & 42 \\
\hline \multirow{2}{*}{ Total } & Rendah & .5254 & .40865 & 24 \\
& Tinggi & .0373 & .33488 & 59 \\
& Total & .1784 & .41921 & 83 \\
\hline
\end{tabular}

Sumber: data primer diolah, 2019 